\title{
Food, Health and Habitat Security of Rural Women in Punjab
}

\author{
Randeep Kaur ${ }^{1}$, Gian Kaur $^{2}$ \\ ${ }^{I}$ Department of Agriculture, Khalsa College, Amritsar, India \\ ${ }^{2}$ Punjab School of Economics, Guru Nanak Dev University, Amritsar, India
}

\begin{abstract}
Food security is the basic human right and is achieved if adequate food is available and accessible for all individuals at all times to live a healthy and happy life. In gender inequality, women are poorly nourished, have less access to health care and live in poor sanitary and household conditions. The main objectives of the study were:

(i) To measure food, health and habitat securities of rural women in Punjab.

(ii) To identify the constraints to her welfare

The study was carried out in all three soil zones of Punjab. Amritsar, Hoshiarpur and Bhatinda district were randomly selected from each soil zone. Multistage stratified random sampling technique was employed. Two blocks from each district and two villages from each block were randomly selected. All the cultivator households were enlisted in three different farm size groups of small, medium and large. 100 women respondents from farm and landless categories were selected from each district making a total sample of 300. Primary and secondary data were collected. Components of livelihood security index (LSI) viz. food and nutrition, health, habitat were assessed by indicators selected from CARE USA/Prog. Div/PHLS. Each of the indicators was measured for availability, accessibility, quality and status on a five point ordinal scale. Food security index points to excellent aggregate mean score of 4.63 for farm category and satisfactory score of 3.61 for landless categories. Diet diversity points to satisfactory score for farm categories and poor score of 2.14 for landless categories. Habitat security points to good score of 3.89 for farm size categories and secured equilibrium with index of 2.86 for land less categories. Water availability and accessibility points to a very good index. Other indices for condition of roof, walls, and freedom of mobility show satisfactory score for both categories. Poor indices for number of rooms, floor and kitchen for the landless were the constraints. Health security points to less than satisfactory equilibrium of 2.86 and fragile equilibrium of 2.53 for farm size and landless categories respectively. Access to government hospital was a constraint in all the districts for both the categories and needs to be improved. Hoshiarpur district performed better in all three indices from all the districts studied.
\end{abstract}

Keywords: Food Security, Fragile Equilibrium, Habitat Security, Household Livelihood Security, Health Security.

\section{Introduction}

Food security is the basic human right. It is achieved if adequate food (quantity, quality, safety and socio-cultural acceptability) is available and accessible for all individuals at all times to live a happy and a healthy life [1]. This definition of food security emphasis availability, accessibility and utilization of food. Inclusion of utilization of food underlines that nutritional security is more than food security. Nutritious and safe diets, adequate biological and social environment, a proper health care to avoid diseases ensure adequate utilization of food.

Food alone is not sufficient to secure a sustainable satisfactory nutritional status and therefore aspects of health must be considered. As a result, nutrition is a function of food intake and health status [2]. Food insecurity may be due to unavailability of food, insufficient purchasing power, inappropriate distribution or inadequate utilization at house hold level. Food insecurity endangers the attainment of Millenium Development Goals, 2015 [3].

Food availability and stability were considered good measure of food security till 1970s. Though India was successful in achieving self sufficiency by increasing food production yet it could not solve the problem of chronic household food insecurity. With the advent of green revolution, food production and availability increased many folds. There after it was recognized that food emergencies and famines were not due to shortage of food grains but due to decline in the purchasing power at the household level [4]. It has become a common practice to estimate the number of food insecure households by comparing the calorie intake with required dietary norms. But nutritionists argue that energy intake is a poor measure of nutritional status which depends upon nutrient intake and on non nutrient food intake. Bouis (1993) suggested two methods to measure food security at household level; growth or depletion of food stocks held over a period of time; $24 \mathrm{hr}$ recall of food consumption for individual member of the household [5]. Rathnayeke and Weehave (2002) measured food 
security by calculating calorie adequacy ratio by dividing individual calorie intake by recommended daily allowance. But it could not show adequacy of nutrients and the recommended level of nutrients [6]. (CARE, 2002), documented standard indicators for measuring food security by estimating calorie adequacy ; diet diversity ; number of meals consumed [7]. (Bentaya, 2009), studied criterion to measure food security by accessing; number of meals consumed; number of different food items consumed; frequency of common food items; frequency of consumption of famine or wild food; number of meals exclusively of staples; percentage of household consuming minimum daily caloric requirement [8].

In many developing countries, though women produce most of the food consumed by the families, yet women rarely have secure tenure to the land they work. Improving access to land for women is essential to increase both food security and sustainable production [9]. Number of constraints limits women's ability to improve their own and their children's nutritional status. In condition of gender inequality, women and girls are poorly nourished throughout their life cycle show higher rate of mortality, have less access to health care and are subject to greater house hold food insecurity [3]. Researchers [10] found that:

1. Females in south Asia consistently fare worse than males on health front while girls in sub Saharan Africa do better than boys. The difference is linked to relative value placed on boys and girls in these two regions.

2. Women are at disadvantage when food and nutrients are distributed within a house hold.

Improvement in house hold welfare depends not only on household income but also on who earns that income. Women, relative to men spend their income over proportionately on food for their family. Their income is more strongly associated with improvement in the health and nutritional status in the children than men's income. Empirical results show that high status of women have a significant positive effect on children's nutritional status [11].

A person is considered to live in absolute poverty when he/she is unable to satisfy his/her basic needsfood, health, water, shelter, education, community participation adequately [12]. Health security is as important as food. A reduced state of health may be due to tenuous access to health care, poor housing and habitat and is worsened by malnutrition which predisposes individuals to diseases. Habitat security ensures access of households to adequate shelter (relevant to local conditions) and related resources to provide healthy and sanitary environment, free from violence/aggression and detrimental elements to enable safe and secure livelihood [7].

To measure progress across nation, World development report was documented. Later new indices like purchasing power parity, physical quality of life index, human development index, gender development index are being used to blend measurement of economic and social progress. These indices are used more for macro level discussion and do little to establish community or household base line data to improve people's lives. Attempts have been made to measure progress at family and community level called the Household Livelihood Security (HLS) approach. It is community assessment technique that identifies the constraints of people's well being as well as their assets and opportunities so as to design effective programmes to overcome the barriers to better health, nutrition, housing, education and livelihood security [13] HLS approach has been piloted extensively at CARE (Centre for assistance and relief everywhere).

CARE USA (2002) documented standard indicators for measuring outcomes of food and nutrition, education, habitat, health and social network Each of the elements were ranked for availability, accessibility, quality and status [14].

CARE India (1996) studied livelihood security of village Tathirasparam in Bastar region of Madhya Pradesh. The results showed that the village was on fragile end of livelihood security index of 1.9 on a scale of one (very poor) to five (excellent). Two-third of girls and half of the boys studied suffered from malnutrition. Less than 4 per cent of the household had latrines. Overall village profile was of limited coping strategy, from months of food insecurity to a longer hunger season, no health services, poor access to potable water and no attention to sanitation [15].

Shymalie and Saini (2008) indicated in their comparative study of Srilanka and Hills of India that the position of women in Srilanka was better in terms of livelihood pointers as compared to Kangra district of India. On the scale of 1 (very poor) to 5 (excellent), food security index was 3.06 and 3.33, health security index was 2.8 and 3.17 and habitat security index was 2.7 and 3.26 in hills of India and Sri Lanka respectively [16].

Punjab's economy is basically agrarian. With the advent of green revolution, production and productivity on the farms increased resulting in increased income and prosperity in the rural areas. Cropping intensity increased from $126 \%$ in $1960-61$ to $190 \%$ in 2011-12 [17]. Per capita income of the state was Rs. 44885 as compared to national average of Rs. 35993 in 2011-12. As per 2011 census, female literacy rate in Punjab was 71.3 per cent as against the national average of 74 per cent .With the spread of literacy and education, women occupy higher status in administrative hierarchy. In spite of their increased participation in different activities both economic and uneconomic, they continue to be discriminated and face hardships in the male dominated society with respect to birth, grooming, consumption, health care, education, religious and social practices, access to use and control and ownership of resources etc. [18]. No research has been conducted till now in 
Punjab to estimate livelihood securities of rural women. Therefore, this study has been conducted to estimate the same, to come out with constraints to her welfare and to come out with appropriate policy to improve their livelihood security.

An attempt has been made in this study to examine three livelihood securities of rural women in Punjab with the following objectives:

(i) To measure food, health and habitat security of rural women in Punjab.

(ii) To identify the constraints to her welfare in terms of better health, food and habitat.

\section{Methodology}

The study was carried out in three randomly selected districts of Amritsar, Hoshiarpur and Bhatinda each from three soil zones of Punjab viz. Central Punjab, Eastern Punjab and South Western Punjab respectively. Multistage random sampling technique was employed to select blocks, villages and households. Two blocks, Chowgawan and Jandiala from Amritsar, Hoshiarpur II and Tanda from Hoshiarpur, Maur and Bhatinda from Bhatinda districts were selected randomly. Two villages from each block were randomly selected. In all, 12 villages were selected from the three districts. All the cultivator households were enlisted and cumulative frequency were obtained and distribution transformed to arrive at three different farm size groups of small, medium and large farm. The small size obtained at was below 2 hectares, medium size between 2-4 hectares and large size above 4 hac. Women respondents from these farm size groups and landless households were enlisted. The household sample included 25 randomly selected households per village making a total sample of 300 in all the three soil regions of Punjab. Sampled household were selected based on probability proportional to their total number. Table 1.1 gives detail of the sample of the study area.

Primary and secondary data were collected to achieve the objectives of the study. Data were collected by household survey on pretested schedule including extensive detailed information on calorie intake, diet diversity, water, sanitation, health status and habitat. Components of livelihood security index were grouped into three security areas viz., food and nutrition, health and habitat. To assess these components, indicators were selected from Standard Menu of Indicators for different Livelihood Securities, CARE USA/Prog. Div/PHLS. Each of the indicators was measured for availability, accessibility, quality and status on a 5 point ordinal scale whose ranges were pre-calibrated according to local norms and requirements.

Table 2.1: Detail of Study Area

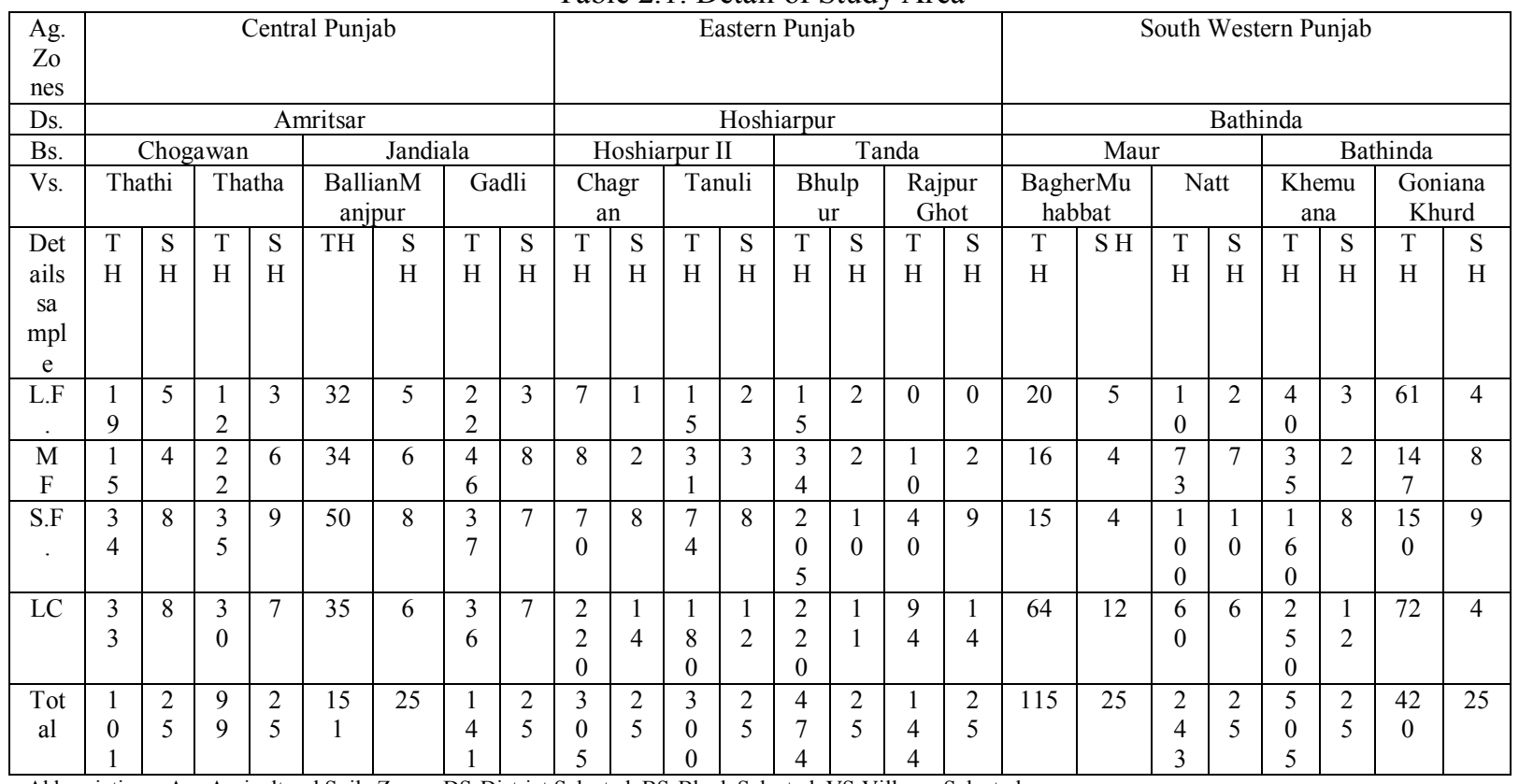

Abbreviations: Ag.-Agricultural Soils Zones, DS-District Selected, BS-Block Selected, VS-Villages Selected

*TH- Total Households and SH-Selected Households

Weighted average score were calculated by scoring various indicators in order of their beneficience / merit on a five point ordinal scale (Likert scale) ranging from 1 to 5 depending upon the importance to each reason. Excellent and well protected securities were ranked 5. Good or protected securities scored greater than 4, satisfactory has been allotted 3 or greater than 3 . Not satisfied score 2 and score 1 indicated poor or serious threat to livelihood security. Fragile equilibrium of 2.5 i.e. midpoint of continuum show most needs met but with periods in which some aspects or security were not achieved. 
With the help of score, weighted average score was computed as below:

$$
\text { Livelihood Security Index }=\frac{1}{\mathrm{fw}} \sum_{\mathrm{w}=1}^{5} \mathrm{w} . \mathrm{fw}
$$

Where

W-score varies from 1-5

fw-number of respondents

The indicators selected for each component and their measurement are given (Table-2.1).

Table2.2: Livelihood Securities Components

\begin{tabular}{|c|c|}
\hline \multicolumn{2}{|r|}{ 1.Health Security Index (Indicators) } \\
\hline a) Accessibility of primary health services & $\begin{array}{l}\text { a) } 0-1 \mathrm{~km} \\
\text { b) }>1-2 \mathrm{~km} \\
\text { c) }>2-4 \mathrm{~km} \\
\text { d) }>4-6 \mathrm{~km} \\
\text { e) Beyond } 6 \mathrm{~km}\end{array}$ \\
\hline b) Accessibility of EOC (Govt. Hospital) & $\begin{array}{l}\text { a) } 0-1 \mathrm{~km} \\
\text { b) }>1-2 \mathrm{~km} \\
\text { c) }>2-4 \mathrm{~km} \\
\text { d) }>4-6 \mathrm{~km} \\
\text { e) Beyond } 6 \mathrm{~km}\end{array}$ \\
\hline $\begin{array}{l}\text { c) Visit of female health worker (based on } \\
\text { services provided) }\end{array}$ & $\begin{array}{l}\text { a) when called for } \\
\text { b) once in a month } \\
\text { c) once in two months } \\
\text { d) once in four months } \\
\text { e) available but no services provided }\end{array}$ \\
\hline d) Access to sanitation facilities & $\begin{array}{l}\text { Scale developed } \\
\text { a) flush toilet } \\
\text { b) Pour flush toilet } \\
\text { c) improved pit } \\
\text { d) traditional pit } \\
\text { e) field/open. }\end{array}$ \\
\hline
\end{tabular}

2. Habitat Security

\begin{tabular}{|c|c|c|}
\hline a) Number of rooms in a dwelling & $\begin{array}{l}\text { Scale developed } \\
\text { a) } 5 \\
\text { b) } 4 \\
\text { c) } 3 \\
\text { d) } 2 \\
\text { e) } 1 \\
\end{array}$ & $\begin{array}{l}5 \\
4 \\
3 \\
2 \\
1\end{array}$ \\
\hline b) Material of roof & $\begin{array}{l}\text { a) Concrete/Plastered } \\
\text { b) Cemented } \\
\text { c) Wood trusses } \\
\text { d) Asbestos sheet } \\
\text { e) Earthen/ Straw }\end{array}$ & $\begin{array}{l}5 \\
4 \\
3 \\
2 \\
1\end{array}$ \\
\hline c) Material of walls & $\begin{array}{l}\text { a) Tiles/pop } \\
\text { b) Cemented } \\
\text { c) Bricks }+ \text { cement } \\
\text { d) Bricks }+ \text { Mud } \\
\text { e) Earthen/straw }\end{array}$ & $\begin{array}{l}5 \\
4 \\
3 \\
2 \\
1\end{array}$ \\
\hline d) Material for floor & $\begin{array}{l}\text { a) Vinyl/marble mosaic } \\
\text { b) Tiles }+ \text { cement } \\
\text { c) cemented } \\
\text { d) bricks } \\
\text { e) Earthen }\end{array}$ & $\begin{array}{l}5 \\
4 \\
3 \\
2 \\
1\end{array}$ \\
\hline e) Road & $\begin{array}{l}\text { a) Gravel/coal tar } \\
\text { b) Concrete } \\
\text { c) Bricks } \\
\text { d) Stone } \\
\text { e) Earthen }\end{array}$ & $\begin{array}{l}5 \\
4 \\
3 \\
2 \\
1\end{array}$ \\
\hline f) Availability of Kitchen & $\begin{array}{l}\text { a) Within the premises with water supply } \\
\text { b)Within the premises without water supply } \\
\text { c) In the Court yard } \\
\text { d) In the living room } \\
\text { e) Open (Chownka) }\end{array}$ & $\begin{array}{l}5 \\
4 \\
3 \\
2 \\
1\end{array}$ \\
\hline g) Availability of water (source) & $\begin{array}{l}\text { a) Drinking water from rural water supply } \\
\text { b) Tubewell } \\
\text { c) Hand pump } \\
\text { d)Community hand pumps/taps } \\
\text { e) Canal or other sources }\end{array}$ & $\begin{array}{l}5 \\
4 \\
3 \\
2 \\
1\end{array}$ \\
\hline
\end{tabular}




\begin{tabular}{|l|l|l|}
\hline h) Accessibility of water supply & $\begin{array}{l}\text { a) Own pipeline inside house (Access in washroom and kitchen) } \\
\text { b) Access either in washroom or kitchen } \\
\end{array}$ & $\begin{array}{l}\text { c)Access only in court yard } \\
\text { d) Piped water outside home 0-2 mint. } \\
\text { e) Common tap line (2-5 mint. Distance) }\end{array}$ \\
\hline 3. Food and Nutritional Security & 3 \\
\hline a) Calorie Adequacy & Amount of Calories consumed in 24h recall method (Table I) \\
\hline b) Diet Diversity & Number of food group consumed out of total of 13 in 24 h recalls. \\
\hline
\end{tabular}

Source: Standard Menu of Indicators for different Livelihood Securities, CARE USA/Prog. Div/PHLS

Table2.3: Energy requirement of Indians in different level of activity.

\begin{tabular}{|l|l|l|}
\hline Levels of activity & Men (body wt.) $60 \mathrm{~kg}$ & Women (body wt.) $55 \mathrm{~kg}$ \\
\hline Sedentary work & 2318 & 1899 \\
\hline Moderate work & 2727 & 2234 \\
\hline Heavy work & 3485 & 2854 \\
\hline
\end{tabular}

Source: A Report of expert group of ICMR (2009) National Institute of Nutrition ICMR - Hyderabad

Table2.4: Food Groups Consumed and dietary diversity survey

a. Grains Staples (Rice, Wheat)

b. Tubers (Sweet Potato, Potato)

c. Green leafy vegetables

d. Other vegetables

e. Dal (pulses)

f. Fruits

g. Meat Fish

h. Eggs

i. Milk and Dairy Product

j. Oils and Fats

k. Sugar/molasses (Gur)

1. Beverages (tea/coffee cock)

m. Soups, snacks

Source: WFP household FS profile VAM analytical approach ODAV (VAM) WFP, Kenya

\section{Results And Discussion}

To realize the objectives of the study, three livelihood securities indices were worked out viz. (i) Food Security, (ii) Health Security, and (iii) Habitat Security

3.1 Food Security Index: Household food security is an important measure of well being and it ensures access to sufficient food for all people at all times. It is not only access to food but also sufficient assess to dietary needs in order to lead a healthy and productive life. The indicators used were:

1. Calorie Adequacy: The amount of food consumed by individual women respondents as measured by using intake technique over a 24 hour recall period. It was calculated by dividing individual calorie intake by recommended daily allowance depending upon the nature of women's work (table-2.3)

2. Diet Diversity: a proxy for nutritional adequacy and essential aspects of food security measures number of different food or food groups consumed per day by a woman from total of 13 food groups using $24 \mathrm{~h}$ recall survey. (Table-2.4)

Table 3.1 indicates food security index for the study area. On a scale of 1 to 5 , calorie adequacy index of 4.58, 4.69 and 4.63 for Amritsar, Hoshiarpur and Bhatinda districts respectively indicates that most households appear to be food secure in case of farm women.

In case of diet diversity, women respondents are shown in the table 3.1, having index of 3.02, 3.21 and 2.78 on a scale of 1-5 which show secured and satisfactory livelihood for Amritsar, Hoshiarpur and less than satisfactory for Bhatinda district respectively. Most farm women consume on an average 8 or fewer food groups daily out of total of 13 . Meat, eggs, fruits are not consumed by majority. Women say that fruit is brought only the day someone visits the city and is not available locally. Even if the fruit or sweets are brought, it is first the prerogative of the male head and then the children. Whatever is left is consumed by the women folks. Milk is seldom consumed except in Bhatinda district where milk is retained more for home consumption than for sale. Network of milk collection centres are very prominent in Amritsar district due to Verka milk plant and as a result average milk consumption of families of this district is less than in Bhatinda district. No in between snacks or munching of food stuff was recorded during survey except in few pockets of Hoshiarpur district where women reported peanuts, corn, seasame seeds in their diet intake. 
For landless categories, on a scale of 1-5, satisfactory calorie adequacy index was 3.32, 3.78 and 3.61 for Amritsar, Hoshiarpur and Bhatinda districts respectively. Diversity in diet show less than fragile equilibrium of 1.98, 2.41 and 1.88 in Amritsar, Hoshiarpur and Bhatinda district respectively with landless consuming 6 or fewer items daily. To save on fuel, some landless category women prefer to make chutney and eat chapattis with it. Tea is consumed only once since an average family consumes half to one litre of milk daily. They consume lot of sugar. Main items of consumption for majority are wheat, pulses or vegetable or chutney, tea, oil and sugar.

For both categories, relatively better food security may be due to agricultural based rural economy in the study villages coupled with cheap atta-dal scheme initiated by the government for the priority section of the society. Deeper analysis indicate that diet pattern of rural women show frequency of common food items. The meals contain maximum of staples. Variation in diet is absent.

3.2 Health Security Index: This index provides clear profile of the constraints to women's health security. The indicators were grouped into four health security areas-

- Accessibility of primary health services (distance taken to access it)

- Accessibility to Govt. Hospital(distance taken to access it.)

- Visit of female health worker (Frequency of visit)

- Access to sanitation facilities available (flush toilet, pour flush latrine, improved pit latrine, traditional pit, no toilet/field

On a scale of 1 to 5 , aggregate health security index for farm women and landless category was estimated to be 2.79 and 2.50 in Amritsar district, 3.41 and 2.82 in Hoshiarpur and 2.51 and 2.13 in Bhatinda districts respectively (Table 3.2). Average Score of 2.85 for the state would put a farm women respondent above fragile equilibrium with most needs met but with periods in which same aspects of security were not achieved District wise analysis of access to primary health services points to satisfactory score of 3.42 in Punjab. The access to the services show satisfactory score (2.99 and 3.04) for Amritsar, satisfactory (3.30 and 3.88) for Bathinda and good for Hoshiarpur district (4.20 and4.29) for farm and landless categories respectively

Score of access to government hospital show poor average score of 1.99 for the state. District wise score of 2.49 points to fragile equilibrium in Amritsar, very poor scores of 1.64 and 1.73 for Bathinda and Hoshiarpur district respectively indicating that access to this facility exceeded beyond $6 \mathrm{~km}$ from the native place. Score of landless categories also points to poor average of 1.80 in the state with very poor score of 1.24 and 1.76 in Bathinda and Hoshiarpur and fragile equilibrium of 2.54 in Amritsar district.

Visit of female health worker (FHW) show less than satisfactory services in the district. The scores show good performance in Hoshiarpur (3.67 and 3.39) as compared to poor score of 2.03 and 1.97 for Bathinda and less than satisfactory (2.75 and2.64) for Amritsar district for farm and landless categories respectively. These services are not very popular with the rural women and many of them were not aware of them.

Sanitary facilities show satisfactory score of 3.27 for farm categories in the state. District wise analysis show excellent score (4.04) for Hoshiarpur, satisfactory (3.04) for Bathinda and less than satisfactory (2.93) for Amritsar. Size wise analysis show large farm of all the districts having very good sanitary facilities (flush latrines) with average score of (4.27), medium farms having satisfactory facilities (3.18) and small farms of Amritsar having poor facilities (2.03) as compared to small farms of Bathinda (2.97) and Hoshiarpur (3.86) with state average of 2.97. Landless categories have very poor average score (1.70) of sanitary facilities. Bathinda scores the minimum (1.44), Amritsar (1.79) and Hoshiarpur (1.89). The respondents either have no latrine at home or few have traditional pits (constructed under the government schemes). Sanitary facilities show excellent average score of 4.27 for the large farmers in the state with Hoshiarpur district leading with 4.80. Data indicate that Hoshiarpur district has better health index score and could be put on secured livelihood security. Bhatinda scores the lowest among the districts with index below fragile equilibrium mid point for landless categories.

The accessibility to government hospital in Hoshiarpur and Bhatinda and access to services of FHW in Bhatinda district are the major constaints observed. In case of landless categories, index for sanitary facilities is also found to be very poor. Small farms of Amritsar have poor sanitary facilities which need improvement.

3.3 Habitat Security Index: The indicators were grouped into 9 areas viz.

- Number of rooms

- Quality of roof

- Quality of walls

- Quality of floor

- Availability of kitchen

- Road condition

- Availability of water 
- Accessibility of water (time taken to access water).

- Freedom of mobility (depend upon extent of safety).

The results of table 3.3 indicate that on a scale of 1-5, habitat security index for farm category women in Amritsar was aggregated to 3.73. The corresponding figures were 4.28 in Hoshiarpur and 3.70 in Bhatinda districts indicating well protected habitat and putting the farm respondents in well secured equilibrium.

Comparison of respondents of landless category in all the districts reveal that in Amritsar and Bhatinda, the index is less than satisfactory but above fragile equilibrium of 2.76 and 2.83 respectively as compared to secured equilibrium of 3.25 of Hoshiarpur district.

Analysis of habitat of farm categories reveal that for large and medium farm sizes and for the three districts, indicators of condition of roof, water availability and accessibility, points to very good score of above 4. Condition of walls and kitchen, point to satisfactory and good score of 3.81 and 4.11 respectively. Condition of road shows satisfactory performance in Amritsar (3.10) and Hoshiarpur (3.63), less than satisfactory but above fragile equilibrium in Bathinda (2.79). Numberof rooms show satisfactory score for Bathinda (3.82), Hoshiarpur (3.83) and Amritsar (3.71). Condition of floor is satisfactory for small farmers (3.02) but excellent for other categories in all the districts. All farmers in Hoshiarpur district show good to excellent score in all the indicator studied as compared to other two districts. Water availability and accessibility, points to good index (4.19 and 4.48) in the state with satisfactory index of 3.93 in Amritsar, good index of 4.59 in Bhatinda for water availability. Very good index for water accessibility (4.48) is estimated for all the districts with excellent index of 5 in Hoshiarpur.

Habitat of landless categories reveal less than satisfactory scores for condition of roof, satisfactory for walls and excellent for availability of water. Other indicators show pathetic habitat conditions. Number of rooms, condition of floor, kitchen, all point to less than fragile equilibrium score of 1.81, 1.96 and 2.15 respectively. District wise analysis show very poor score of 1.46 and 1.44 for number of rooms; 1.43 and 1.53 for floor and 1.43 and 1.97 for kitchen in Amritsar and Bathinda respectively. Corresponding score for Hoshiarpur district show fragile equilibrium of 2.24, 2.53 and 2.67 Landless rural women in Hoshiarpur district have better access to all these indicators due largely to the fact that one or more members of some of the families were residing abroad and sending money on regular basis. Same explanation can be extended to small farmers of Hoshiarpur district who have less average size of farm as compared to Amritsar and Bhatinda districts but are enjoying better habitat securities due to foreign connection of many families.

Habitat security points to satisfactory and secured aggregate index of 3 for landless and 3.86 for farm size categories in the state with Hoshiarpur district performing the best. Bhatinda district had the best availability of drinking water with R.O. system installed by the government in all the villages studied. Hoshiarpur respondents have the best availability of kitchen with-in the premises and with best fitting of inner water supply with excellent index value of 4.84 for farm size categories. Large and medium farm sized categories from all the districts could boast of a very good habitat. Credit goes o the prosperity ushered by green revolution in the rural Punjab. Large and medium farmers could flaunt marbled and tiled floors, granite fitted kitchens and washrooms, large terraces, cars, motorcycles, air conditioners and generators. Street or road condition is average in all the villages for both the categories studied. Major constraints observed in habitat in case of farm categories are poor floor conditions for small farms of Amritsar and Bhatinda district with values falling below fragile equilibrium. For landless category habitat, number of rooms, poor floor condition and availability of kitchen are the constraints in Amritsar and Bhatinda district.

Freedom of mobility index show good index of 3.68 and 4.06 for farm and landless categories respectively. District wise analysis show satisfactory index of 3.03 for Bhatinda as compared to best mobility of 4.06 for Amritsar and 3.99 for Hoshiarpur. Women in Maur block of Bhatinda claimed that they had never gone alone or independently to hospital, fair, market or to meet their kin. Landless categories enjoyed very good mobility index of 4.06 with best index for Amritsar (4.50), Hoshiarpur (4.40) and Bhatinda (3.40). 
Table 3.1: Food Security index

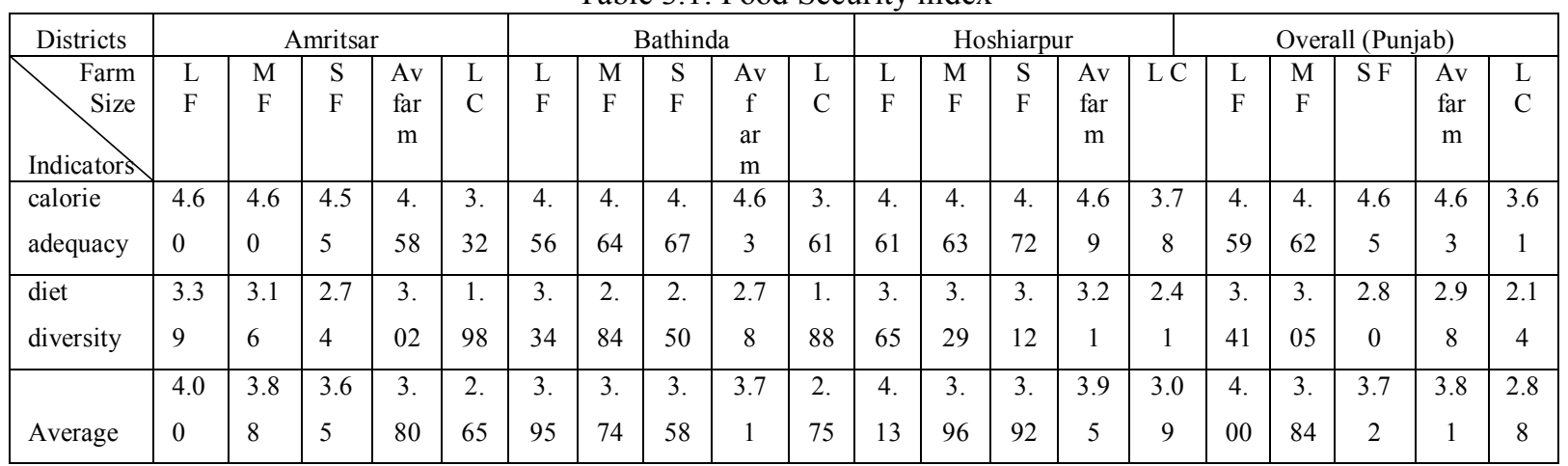

*LF-Large Farmer, MF-Medium Farmer, SF-Small Farmer, LC-Landless Category and Av Farm - Wt. Average of all farm sizes

Table 3.2: Health Security Index

\begin{tabular}{|c|c|c|c|c|c|c|c|c|c|c|c|c|c|c|c|c|c|c|c|c|}
\hline Districts & \multicolumn{5}{|c|}{ Amritsar } & \multicolumn{5}{|c|}{ Bathinda } & \multicolumn{5}{|c|}{ Hoshiarpur } & \multicolumn{5}{|c|}{ Overall (Punjab ) } \\
\hline $\begin{array}{l}\text { Farm } \\
\text { Sizes }\end{array}$ & LF & $\mathrm{MF}$ & S F & $\begin{array}{c}\text { Av } \\
\text { farm }\end{array}$ & $\mathrm{L} \mathrm{C}$ & $\mathrm{LF}$ & MF & $\mathrm{SF}$ & $\begin{array}{l}\text { Avf } \\
\text { arm }\end{array}$ & $\mathrm{LC}$ & LF & $\mathrm{MF}$ & S F & $\begin{array}{c}\mathrm{Av} \\
\text { farm }\end{array}$ & $\mathrm{LC}$ & $\mathrm{LF}$ & MF & $\mathrm{S} \mathrm{F}$ & $\begin{array}{c}\text { Av } \\
\text { farm }\end{array}$ & $\mathrm{LC}$ \\
\hline $\begin{array}{l}\text { Access to } \\
\text { primary } \\
\text { health } \\
\text { services }\end{array}$ & 2.88 & 3.00 & 3.03 & 2.99 & 3.04 & 3.69 & 3.05 & 3.32 & 3.30 & 3.88 & 4.00 & 4.33 & 4.20 & 4.20 & 4.29 & 3.35 & 3.24 & 3.54 & 3.42 & 3.86 \\
\hline $\begin{array}{c}\text { Access to } \\
\text { govt. } \\
\text { hospital }\end{array}$ & 2.50 & 2.42 & 2.53 & 2.49 & 2.54 & 1.46 & 1.82 & 1.58 & 1.64 & 1.24 & 1.60 & 1.67 & 1.77 & 1.73 & 1.76 & 1.97 & 2.06 & 1.96 & 1.99 & 1.80 \\
\hline $\begin{array}{c}\text { Services } \\
\text { of female } \\
\text { health } \\
\text { worker }\end{array}$ & 2.81 & 2.83 & 2.66 & 2.75 & 2.64 & 2.15 & 1.95 & 2.03 & 2.03 & 1.97 & 3.80 & 3.89 & 3.60 & 3.67 & 3.39 & 2.70 & 2.65 & 2.80 & 2.74 & 2.78 \\
\hline $\begin{array}{l}\text { sanitary } \\
\text { facilities }\end{array}$ & 4.25 & 3.25 & 2.03 & 2.93 & 1.79 & 4.08 & 2.64 & 2.97 & 3.04 & 1.44 & 4.80 & 4.33 & 3.86 & 4.04 & 1.82 & 4.27 & 3.18 & 2.98 & 3.27 & 1.70 \\
\hline Average & 3.11 & 2.88 & 2.56 & 2.79 & 2.50 & 2.85 & 2.37 & 2.48 & 2.51 & 2.13 & 3.55 & 3.56 & 3.36 & 3.41 & 2.82 & 3.07 & 2.78 & 2.82 & 2.85 & 2.53 \\
\hline
\end{tabular}

Table 3.3: Habitat Security Index

\begin{tabular}{|c|c|c|c|c|c|c|c|c|c|c|c|c|c|c|c|c|c|c|c|c|}
\hline Districts & \multicolumn{5}{|c|}{ Amritsar } & \multicolumn{5}{|c|}{ Bathinda } & \multicolumn{5}{|c|}{ Hoshiarpur } & \multicolumn{5}{|c|}{ Overall (Punjab) } \\
\hline$r$ & $\mathrm{LF}$ & MF & S F & $\begin{array}{l}\mathrm{Av} \\
\text { farm }\end{array}$ & $\mathrm{LC}$ & LF & MF & S F & $\begin{array}{l}\text { Avf } \\
\text { arm }\end{array}$ & $\mathrm{LC}$ & LF & MF & S F & $\begin{array}{l}\text { Av } \\
\text { farm }\end{array}$ & $\mathrm{LC}$ & LF & MF & S F & $\begin{array}{c}\text { Av } \\
\text { farm }\end{array}$ & $\mathrm{LC}$ \\
\hline Indicators & & & & & & & & & & & & & & & & & & & & \\
\hline Rooms & 4.81 & 4.33 & 2.69 & 3.71 & 1.46 & 4.77 & 4.14 & 3.19 & 3.82 & 1.44 & 5 & 4.44 & 3.51 & 3.83 & 2.24 & 4.82 & 4.27 & 3.14 & 3.78 & 1.81 \\
\hline Roof & 4.81 & 4.5 & 3.56 & 4.15 & 3 & 3.85 & 4.05 & 3.68 & 3.84 & 3.15 & 5 & 4.89 & 4.86 & 4.88 & 3.55 & 4.47 & 4.38 & 4.06 & 4.23 & 3.29 \\
\hline Walls & 4.06 & 4 & 3.19 & 3.65 & 2.79 & 4.08 & 3.86 & 3.55 & 3.76 & 3.62 & 4.6 & 4.33 & 4 & 4.12 & 3 & 4.15 & 4 & 3.59 & 3.81 & 3.13 \\
\hline Floor & 3.63 & 3.67 & 2.22 & 3.02 & 1.43 & 4.46 & 3.55 & 2.26 & 3.12 & 1.53 & 4.6 & 4.11 & 4.14 & 4.18 & 2.53 & 4.09 & 3.69 & 2.92 & 3.36 & 1.96 \\
\hline Road & 3.06 & 3.21 & 3.03 & 3.1 & 2.68 & 2.62 & 2.77 & 2.87 & 2.79 & 2.53 & 3.8 & 3.44 & 3.66 & 3.63 & 3.08 & 3 & 3.07 & 3.2 & 3.13 & 2.82 \\
\hline Kitchen & 4.44 & 4.08 & 3.13 & 3.74 & 1.43 & 4.77 & 4.18 & 3.48 & 3.97 & 1.97 & 4.8 & 4.89 & 4.83 & 4.84 & 2.67 & 4.62 & 4.25 & 3.85 & 4.11 & 2.15 \\
\hline Water availability & 4.31 & 4.17 & 3.56 & 3.93 & 4.57 & 4.62 & 4.64 & 4.55 & 4.59 & 4.65 & 4 & 4.11 & 4 & 4.02 & 4.2 & 4.38 & 4.35 & 4.03 & 4.19 & 4.43 \\
\hline Water accessibility & 5 & 4.42 & 3.72 & 4.24 & 3 & 4.85 & 4.27 & 4.19 & 4.35 & 3.21 & 5 & 5 & 5 & 5 & 3.55 & 4.94 & 4.45 & 4.33 & 4.48 & 3.31 \\
\hline Mobility & 4 & 4.05 & 4.1 & 4.06 & 4.5 & 2.8 & 2.95 & 3.2 & 3.03 & 3.4 & 4 & 3.9 & 4.02 & 3.99 & 4.4 & 3.52 & 3.6 & 3.79 & 3.68 & 4.06 \\
\hline Average & 4.24 & 4.05 & 3.24 & 3.73 & 2.76 & 4.09 & 3.82 & 3.44 & 3.70 & 2.83 & 4.53 & 4.35 & 4.22 & 4.28 & 3.25 & 4.22 & 4.01 & 3.66 & 3.86 & 3.00 \\
\hline
\end{tabular}

*LF-Large Farmer, MF-Medium Farmer, SF-Small Farmer, LC-Landless Category and Av Farm- Wt. Average of all farm sizes 


\section{Conclusion}

The purpose of this study was to assess three livelihood securities (food, health and habitat) of rural women in Punjab, identify the constraints to her welfare so that suitable policies can be designed to improve their livelihood. Three different livelihood outcomes for women were assessed in three randomly selected districts of Punjab.

The findings reveal

- Food security index points to secured equilibrium of 3.81 for farm women and 2.88 for landless category. Relatively better food security in the entire district may be due to agricultural based rural economy in the study area coupled with introduction of atta-dal scheme for the target group. Diet diversity index points to less than satisfactory score of 2.98 and 2.14 for farm sized and landless category rural women. Farm sized and landless consume on an average 8 and 6 food items out of total of 13, respectively. The diet pattern of both categories show frequency of common food items, the meals contained maximum of staples. Variation in diet was found absent.

- Availability and accessibility of health services indicate that aggregate health score in Punjab is beyond fragile equilibrium with values of 2.85 and 2.53 in case of farm and landless rural women respectively and more needs to be done to develop satisfactory health livelihood security. For the state as a whole, access to govt. hospital was a major constraint for both categories as revealed by poor index of 1.99 and1.80. Access to primary health services points to satisfactory index of 3.42 with best score in Hoshiarpur and satisfactory in other two. Very poor availability of sanitary facilities is indicated by the aggregate score of 1.70 for landless categories as compared to satisfactory for farm categories. Accessibility to government hospital and services of health extension workers were observed to be reasons behind low index score. Hoshiarpur district stood comparatively in a better position in health status as compared to Amritsar and Bhatinda due largely to greater access to primary health and female health services though access to govt. hospital was again a major constraint for both categories of rural women.

- Habitat security in the state points at good to satisfactory index for farm and landless category rural women respectively with Hoshiarpur district performing better than Amritsar and Bhatinda districts. Indices of roof, kitchen, water availability and accessibility points to very good score. Satisfactory index score is estimated for conditions of walls, kitchen. Street or road condition is satisfactory in Amritsar and Hoshiarpur but less than satisfactory for Bhatinda district .Number of rooms show less than satisfactory score for small farmers in Amritsar district. Condition of floor was less than satisfactory (2.92) for small farmers in all the districts but excellent for other farm categories . Satisfactory index score is assigned for condition of roof, walls and availability of water whereas condition of floor (1.96), number of rooms(1.81) and kitchen (2.15) is poor and a constraint for the habitat for landless category. Under various housing schemes of the centre/ state government, single room houses have been provided to the target groups in some of the villages which contributed in improving the habitat index for the landless for roof, walls and availability of water. However, still more needs to be done for improving the habitat index.

\section{REFERENCES}

[1] WHO(2000).Food and Nutritional security.www.foodsecuirty.org/DL/course/shortcourseme Fa/en/pdf.

[2] Gross, R., Schoeneberger, Hans, Pfeifer Hans, Joachim Hans and Preuss A (2000). The four dimensions of food and nutrition security: definitions and concepts. www.foodsec.org/DL/Course

[3] UNSCN, (2004). $5^{\text {th }}$ report on the world nutrition situation.Nutrition for improved development outcomes. Geneva. Original not seen, assessed in LiobaWeingoetner (2009). The concept of Food and Nutrition security. In Went-IntenrationaleWeilibildung.

[4] Weingartner, Lioba (2009). The concept of food and nutritional security. Achieving Food and Nutritional Security.InWentInternationaleWeitbildunggGmbH Klaus, Klennert @ inwent.org.www.inwent.org.

[5] Bouis, H. (1993). Food Consumption Survey: How random are measurement errors? New directionS for household surveys, ed. J. Von Braus and D. Pietz, 219-231. Washington, DC: International Food Policy Research Institute.

[6] Rathnayeke, Ishara and Weeraheva, Jeevika. (2002 ). An assessment of Intra household allocatinon of food: A case study of urban poor in Kandy. Sri Lanka Journal of Agricultural Economics, vol. 4, part I, pp. 95-105.

[7] CARE (2002). Impact guidelines Part II: Menu of Standard Indicators for HLS. Impact Care USA/Program Division/ PHLS.

[8] Bentaya, Maria Gerster (2009). Assessment and analysis of the food and nutrition security situation at Micro and Meso level. In Went-International WeilbildunggGmbH Klaus, Klennet @ inwent.org.www.inwent.org.

[9] FAO (2002).The state of food insecurity in the world 2002. Rome. Assessed from Weingartner, Lioba (2009).The concept of food and nutritional security.Achieving Food and Nutrition Security. InWent-InternationaleWeitbildunggGmbH Klaus, Klennert@ inwent.org.www.inwent.org.

[10] IFPRI (1999).Women, the key to food security looking into the household. www.ifpri.org..

[11] Quisumbing, A.R. et al. (1995). Women: The key to food security IFPRI Food Policy Report Washington. Original not seen, accessed in Weingartner, Lioba (2009), The Concept of Food and Nutrional Security.Achieving food and Nutrition Security.A Training Course Reader inWent - international weitebilding g GmbH Klaus.Klennert@inWent. Org.www.inWent.org.

[12] Frankerberg, T. and McCaston, M.K. (2000).Operationalizing household livelihood security. A holistic approach for addressing poverty and vulnerability program document: CARE USA, Atlantic, GA: Care. http://www.fao.org/docrep

[13] Drinkwater, M. (1998). Participating in livelihood assessment (Original not seen, cited in Linderberg, M. (2000) Measuring household livelihood security at the family and community level in the developing world. www.elsevier.com/locate/worlddev). 
[14] CARE, USA (2002). Household Livelihood Security Assessment.A tool kit for practioners. TANGO International Inc. Tuccon, Arizona. www.tangointernational.org/thesis/...

[15] CARE, India (1997). Household livelihood security assessment. Report Bastar, Madhya Pradesh, India. CARE, April 8-28 (Original not seen, cited in Linderberg, M. (2000) Measuring household livelihood security at the family and community level in the developing world. www.elsevier.com/locate/worlddev).

[16] Shymalla, H.W. and Saini, A.S. (2008).Socioeconomic status and livelihoods security of women: Comparative study of Hills of India and Sri Lanka. e-google-books.Readworthy Publications.

[17] Government of Punjab (2011 -12).Statistical Abstract of Punjab. Economic and Statistical Organization, Chandigarh.

[18] Ghuman, Gurmeet Singh (2006), Female participation in agricultural activities in sub-mountainous region of Punjab, Ph.D. Thesis, Guru Nanak Dev University, Amritsar, India. 